\title{
The assimilation of complex accounting concepts using the Cognitive Load Theory as a framework
}

\author{
El potencial de la teoría cognitiva en la enseñanza de la \\ contabilidad y auditoría
}

Anne M. Garvey (anne.garvey@uah.es)

Universidad de Alcalá (Spain)

Laura Parte (Iparte@cee.uned.es)

Universidad Nacional de Educación a Distancia (UNED) (Spain)

José Antonio Gonzalo Angulo (josea.gonzalo@uah.es)

Universidad de Alcalá (Spain)

RESUMEN: El artículo examina la asimilación de dos conceptos contables complejos: la imagen fiel (TFV) y el valor razonable (FV) en una muestra de estudiantes de Contabilidad Financiera. El objetivo es evaluar la opinión de los estudiantes sobre TFV y FV durante su educación y detectar si las percepciones cambian con su nivel académico y madurez. La metodología utilizada es una encuesta de opinión. Las respuestas obtenidas muestran que los estudiantes consideran que la TFV es un concepto superior a otros principios contables. Además, en el estudio se observa que las respuestas de los estudiantes dependen del nivel académico y la madurez. Por último, se considera que los postulados que establece la teoría cognitiva podrían servir a los instructores en materia de contabilidad y organismos reguladores para mejorar el proceso de aprendizaje así como la calidad de la información financiera.

PALABRAS CLAVE: Conceptos contables complejos; Teoría cognitiva; Valor razonable; Aprendizaje en Contabilidad; Imagen fiel.

\begin{abstract}
This paper examines the understanding of two complex accounting concepts: true and fair view (TFV) and fair value (FV) by students in Financial Accounting. The correct assimilation of these concepts is assessed as to whether there are differences in concept perception due to academic level and maturity. We use a survey to examine the perception and assimilation of the TFV and FV. The evidence suggests that accounting students consider that TFV is a superior accounting concept over other accounting principles. Additionally, the study identifies a pattern of change depending on the academic level and maturity of the participants. On discovering differences, a proposal is made to use the Cognitive Load Theory (CLT) by standard setters and instructors in accounting and auditing to improve the learning process and the quality of financial information.
\end{abstract}

KEYWORDS: Complex Accounting Concepts; Cognitive Load Theory; Fair Value; Learning processes in Accounting; True and fair view.

Artículo. Recibido: 05-07-17 - Versión revisada: 18-07-17, Aceptado: 04-09-17

Licencia Creative Commons BY NC ND · 2017 • Asociación Española de Contabilidad y Administración de Empresas - AECA 


\section{Acknowledgments}

We acknowledge the help of several Spanish Universities, the Auditing School of the ICJCE (Instituto de Censores Jurados de Cuentas de España) and AECA (Asociación Española de Contabilidad y Administración de Empresas) for facilitating the distribution of the survey and arranging some interviews. We gratefully acknowledge the help from several prestigious researchers for suggestions about the survey and interview design.

We also appreciate the valuable comments made by Horacio Molina and Mar Camacho and the comments from the workshop participants at the $2014 \times$ Workshop on Empirical Research in Financial Accounting, at the 2014 European Accounting Congress (EAA) and at the 2015 XX Workshop on Accounting and Management Control.

The authors acknowledge the financial contribution from the Spanish Ministry of Innovation and Science (research projects DER2009-09539, ECO2010-17463, ECO2010-21627, DER2012-33367, DER2015-67918P), Castilla-La Mancha regional Ministry of Education and Science (research Project POll10-0134-5011) and Alcalá University, Madrid (research project CCG20014/HUM-036).

\section{INTRODUCTION}

The objective of this paper is threefold. Firstly, it is to assess the perception of True and Fair View (TFV) and Fair Value (FV) by undergraduate and postgraduate students and to ascertain if they consider that the financial information can show a TFV by applying the FV rules and to what extent that information is better than by applying historical cost rules. Our second intention is to establish whether students' perceptions of these concepts change as a result of academic level and maturity. Our final aim is then to make a proposal for the use of the benefits obtained from the reduction of cognitive loads in order to improve the learning process relating to complex accounting concepts and therefore improve the quality of financial information. When analysing the reduction in cognitive loads, we examine a psychology theory called "The Cognitive Load Theory" (CLT) which we will explore and apply to our particular study in order to make our proposal.

We believe that both TFV and FV are complex accounting concepts for students because they imply some philosophical thinking and ethical attitudes which tend to be still in formation during third level studies. They are also related to the usefulness of financial reporting for decision making in uncertain scenarios. We should of course, emphasis that we do not consider them to be of equal complexity or that they should necessarily be treated in the same way. Our intention is to discover students' perceptions of these accounting terms, to evaluate if the perceptions change with maturity and academic level and to make some proposals for improvement in student learning, which we consider is an important final implication to improve the overall quality of accounting professionals and financial information.

It is also relevant to mention that the TFV concept is becoming an important concept in many countries and has special assimilation difficulties in countries that use a codified legal system. It became mandatory for European Union (EU) member countries from the late eighties. As a consequence, TFV becomes the 'final objective' to be reached by the financial information prepared by companies and it is a rooted concept in many legislations. The FV is one of the more recent complex concepts introduced into financial reporting; it becomes an interesting method to examine especially after the introduction of the International Accounting Standards issued by IASB and the subsequent changes in national legislations.

Indeed we could have used another set of variables to better characterize the sample but we choose two elementary variables (educational level and maturity) that are 
representative of our sample and participants. As the sample is formed by accounting undergraduates and postgraduates enrolled in an Auditing Master, the educational level and degree of experience are key factors because they condition the access to obtaining auditor status.

The survey contains 11 unique questions. We divided the survey into three sections to analyse and present the results. The first section of the survey relates to students' perception of the TFV, the second section to their perception of FV and the third section to their perception of whether the use of FV in financial accounting can achieve the TFV. It is the third section of our survey that we use in order to make our proposal using the CLT as our framework. It is here where we can observe students' understanding and assimilation of the complex concepts we are analysing.

The results suggest that accounting students consider that TFV is a superior accounting concept over other accounting principles and that the TFV is the final objective of the financial statements learnt during the education process. The study also identifies a pattern of change depending on the academic level and maturity of the participants. The results have some implications in the learning process of complex concepts in accounting considering the CLT. The outcome shows that efficiency in the learning process of complex concepts in accounting is of utmost importance. The reduction of the different cognitive loads could have an important positive impact on the understanding and interpretation of complex accounting concepts.

The study is structured in the following way: the next section provides an explanation of the conceptual framework based on the conceptual assessment of CLT, the application of CLT to TFV and FV and the application of the CLT to education level and maturity. The third section presents the research hypotheses and methodology, and the fourth section shows the survey design. The fifth section discusses the results and the final section provides our concluding remarks.

\section{CONCEPTUAL FRAMEWORK: THE ASSIMILATION OF COMPLEX CONCEPTS}

\subsection{Cognitive Load Theory (CLT)}

The cognitive load theory was discovered by Miller in the 1950's and was developed by Sweller in relation to instructional design in the 1980's. CLT explains that the working memory of an individual has a limited capacity and the composition of the cognitive load and the presentation of the information will affect how an individual understands the information being learnt (Ginns, 2006; Ragland and Reck, 2016). The working memory can be highly loaded when dealing with complex concepts and it is therefore important to use the loads efficiently in order to maximise the final knowledge acquisition correctly. In particular, the theory maintains that there are three types of cognitive load which affect the working memory of an individual; they are intrinsic load, extraneous load and, finally, germane load.

The first of the three relates to the complexity of the information to be assimilated. It is important to observe that this load refers to the nature of the information and also to the individual's prior knowledge of this material (Kalyuga and Sweller, 2004). This load can only be reduced by lowering the complexity of the material or by an individual's prior knowledge of the area (Van Gerven et al., 2000; Van Merrienboer and Sweller, 2005).

The second area is called the extraneous load and focuses on the way the information is presented. In order to reduce this load, it is necessary to present the information in a way that is easy to understand, or as easy as possible to understand in the case of complex concepts like TFV and FV. In order to make financial information useful for 
decision-makers it would be important to study carefully the presentation format to free up space in the area of working memory.

And finally, the third area is referred to as the germane load. This area is used for knowledge acquisition. Here the information is processed, constructed and placed into schemes inside the memory. The construction of adequate and sophisticated schemata is therefore very important in complex learning tasks because they require more effort to be assimilated; by using schemes, the elements to be learnt in the material are highly interconnected and this facilitates the learning process (Kirschner, 2002).

According to this theory, it therefore can be observed that the more knowledge an individual has of the complex concept and the way it is presented can free up space in the working memory to help in the efficiency of task performance. Including schemes of how to achieve the objective of these complex concepts in the learning process could help in the area of the germane load. This would indicate the necessity of effective learning structures in accounting courses in general but especially when dealing with concepts of complexity. It also indicates, therefore, that the presentation of this information in the financial statements is of extreme importance in order to allow users to take more efficient decisions.

In sum, cognitive load depends on causal and assessment factors. The first one includes the characteristics of the participants (e.g., age and cognitive abilities), the task (e.g., task complexity and time pressure), the environment (e.g., noise and temperature), and their mutual relations. Assessment factors include mental load, mental effort, and performance as the three measurable dimensions of cognitive load (see Paas and Van Merrieënboer, 1994; Van Gerven et al., 2000).

\subsection{Application of the Cognitive Load Theory to TFV and FV}

Studies with a TFV focus have shown that subjects which require a more advanced level of knowledge or sophistication about accounting information exhibit a certain degree of cognitive complexity (Houghton, 1987). The interpretation and assimilation of TFV by users (professionals and non-professionals, preparers and users) has occupied a relevant position in early literature. Houghton (1987) analyses the meaning and interpretation of TFV by professional users and the results show that both share different cognitive structures when the meaning of TFV is tested. Alexander and Jermakowicz (2006) explain that the content of financial statements are inherently subjective and are influenced by intersubjective constructions rather than mind-independent realities. The human mind can have a variety of motivations and the flexibility and the possible interpretation of accounting regulation make it almost impossible for accountants to act in the same manner even when the accounting rules or guides indicate exactly what to do in each situation.

In order to show how the CLT can affect the perception and assimilation of the TFV concept, we shall examine here the fact that TFV does not come with a definition. A concept with no definition makes it open to interpretation and, therefore, marks it as more complex to apply in practise. This renders a higher intrinsic load. Additionally, the less knowledge one has of the accounting rules will affect this load in a negative way. This intrinsic load could be decreased by the introduction of a definition of TFV or by an increased knowledge by students of the accounting rules. However, we already know that, in accounting, the introduction of a definition may not be feasible. According to Garvey (2012), a strict definition of TFV cannot work but, where a definition is not possible, guides could be introduced on how to obtain it or how it cannot be achieved. 
The introduction of guides would lower the intrinsic load but would also lower the germane load by having some schemes of complex concepts that are easier to assimilate by students and users. The presentation of the guides and the financial information would also help to reduce the extraneous load. With the above explanation, we are not, at least for the moment, suggesting the introduction of a definition or guides for TFV application but simply demonstrating how these complex concepts affect the working memory of an individual and how this finally impacts their assimilation and the overall performance of their interpretation in reality.

The reduction of the loads would be similar to that mentioned already for TFV in the case of FV. The FV concept is defined by the IASB in IFRS 13: Fair Value Measurement as the price that would be received to sell an asset or paid to transfer a liability in an orderly transaction between market participants at the measurement date. The definition is clear but its complexity comes about because we are depending on available markets for obtaining this measurement, markets that may not always be very active and values that may need to be substituted for amounts based on mathematical formulae. Once again, in order to be applied properly, the concept requires a good base knowledge of the underlying accounting standards and the use of judgement in order to decide which method to use or whether FV should be used at all. This is a process that is not accessible to introductory students and an ability which is acquired over the years when practising as an accountant. These arguments justify the use of CLT as our conceptual framework.

The role of presentation of accounting information has gained momentum in recent accounting research due to its importance to decision-making for sophisticated investors (Maines and McDaniel, 2000; Libby and Emett, 2014) and unsophisticated users (Maines and McDaniel, 2000; Clor-Proell et al., 2010; Ragland and Reck, 2016; Kooce et al., 2011; Libby and Emett, 2014). For example, Clor-Proell et al. (2010) argue that non-sophisticated investors view firms with different $\mathrm{FV}$ inputs as having differentially reliable financial statements. Kooce et al. (2011) show that investors' judgments of FV relevance are sensitive to the context causing differences in judgment about firm value. Therefore, findings suggest that the presentation format influences nonprofessional users' when making their judgments (Maines and McDaniel, 2000; ClorProell et al., 2010; Kooce et al., 2011; Libby and Emett, 2014). That is, assuming that extraneous load is affected by the way the information is presented, the TFV and FV presentation might influence users' decisions about firm value.

The use of $\mathrm{FV}$ has long been debated and more in the recent financial crisis. A key question of FV is how users understand and judge the relevance of FV (Koonce et al., $2011)$. Therefore, the knowledge acquisition of $\mathrm{FV}$ and hence the elements contained in the complex learning task play an important role in our study. These arguments justify the use of CLT as our conceptual framework.

\subsection{Application of the Cognitive Load Theory to Education Level and Maturity}

Gonzalo Angulo et al. (2017) show differences between auditors in public practice and non-professional users in relation to the strict compliance of accounting rules and the fulfilment of TFV and to the imposition of fines when the TFV is not achieved by following the accounting standards. Also, Garvey et al. (2017) reveal that academics and students do not share similar cognitive structures when the TFV concept is explored. The CLT can help to understand the results as well as the different cognitive schemes in problem solving between academics and students when they deal with complex concepts such as TFV. 
In our analysis, we have also introduced two further factors which we understand affect the load level in the assimilation and perception of TFV and FV; they are education level and maturity. This can be explained through psychological methods, such as the CLT, because, as examined earlier, the results obtained from processing information is directly related to the make-up of the intrinsic, extraneous and germane loads from that incoming information.

Arquero and Tejero (2011) detect that accounting students present different learning styles compared with other social sciences. In addition, they find that learning styles depend on gender and age (Arquero and Tejero, 2006 and 2011). It seems that older students (or more mature students) are more independent when considering participant styles while young students (or less mature students) are more avoidant and competitive (Arquero and Tejero, 2006).

Anderson et al. (2013) consider that it is important to know how undergraduate and graduate students learn the fundamental concepts of accounting. In their experiment, they detect that students follow a 'forward based' pedagogical approach that provides a scarce perspective to the use of the concepts learnt; a relatively narrow procedural perspective is shown on how to use such knowledge.

We already have evidence which indicates that novices and experts deal with the strategies of problem solving in different ways. Novices use a means-end analysis. This suggests that they look at the goal and then work backwards by setting sub goals (Sweller, 1988). As they lack the expertise, they have not as yet been able to introduce the information into schemes so they must process everything in order to find the solution. This requires the use of huge amounts of memory space and leaves little, if any, space in the cognitive load. Experts, on the other hand, are able to move forward by identifying the problem to be solved with their previous experience. They have stored these experiences in schemes in the Germane load section. These cognitive structures or schemes help individuals to identify the problem as belonging to a particular group which then enables them to identify the solution for this case (Sweller, 1988).

Therefore, we build our hypothesis using the cognitive load theory framework. Figure 1 summarises the effects of cognitive load on an individual's judgement and decisions adapted to TFV and FV concepts. In particular, our interest is to examine how educational level and maturity affect the students' understanding of TFV and FV.

Figure 1: Framework of cognitive load theory

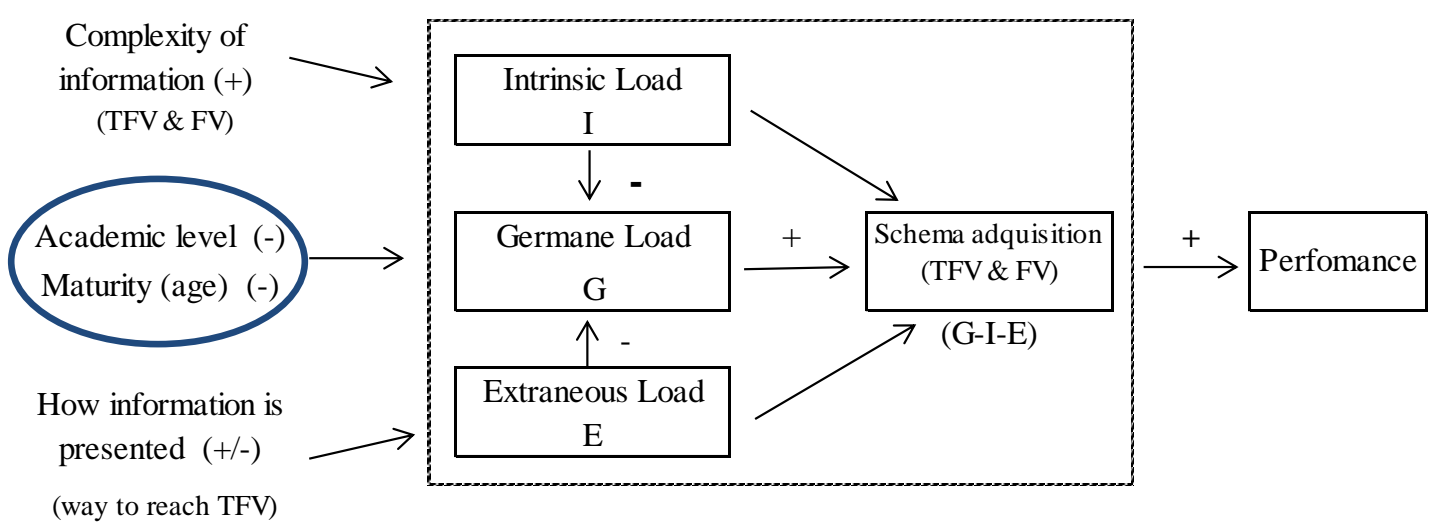

Source: Adapted from Cognitive load theory

educade, no 8,2017 , p. 40 


\section{RESEARCH HYPOTHESES AND METHODOLOGY}

\subsection{Hypotheses}

Examining students' views on the understanding of TFV and FV may give a more complete picture of the overall effects of these complex concepts. Prior literature shows that the meanings held by inexperienced members of the accounting profession are not the same as those held by practicing accountants (Houghton and Hronsky, 1993). Then our first hypothesis investigates the perception of TFV and FV reached by students during the learning context.

H1: There are not differences in the perception of TFV and FV reached by students during the learning context

However, the comprehension of these complex accounting concepts (TFV and FV) depends on the degree of previous knowledge in the area. The accounting and education literature support this argument. Rich et al. (1997, p. 105) cite several studies which document that auditor judgment is shaped by specific prior experiences of the audit process, of client misstatement and persuasion and of the client or industry. Frederick (1991) performs an experiment with auditors and auditing students to investigate the incidence of expertise and to understand the cognitive skills of expert and novel auditors. Findings show differences in schematic knowledge and memory structures between experts and novices.

Hamilton and Ó'Hógartaigh (2009) also talk about the educational effect of becoming an accountant. They maintain that TFV is the product of the relation between the linguistic habitus of the accountant and the field of accounting. They also suggest that auditors are social agents in the accounting field whose habitus is formed and acquired by the process of inculcation during their educational and training period. They refer here to the fact that in order to become a member of a professional accounting body, you must follow the rules that have been established by these very bodies. They inculcate in their future members the understanding and meaning of the terms which are included as part of their training material. In other words, they suggest that accountants' perception of accounting terms is highly dependent on the professional body that they aspire to be a member of and the firm where they carry out their training as they become part of the habitus of the firm and the accounting body. Then our interest is to assess whether undergraduate and postgraduate accounting students' perception of these crucial concepts is similar. Then our second hypothesis is specified as:

H2: The perception of TFV and FV reached by students and their processing issues do not depend on their educational level.

The importance of maturity in the assimilation of accounting concepts is essential due to its complexity. Rankin et al. (2003, p. 372) argue that 'mature students and school leavers are likely to differ in terms of preferences, attitudes toward study and selfregulation'. Theuri and Weickgenannt (2008) analyse the effect of major accounting scandals according to age, sex, class standing and the number of accounting classes taken by students. The evidence suggests a clear link of the effect of accounting scandals on students' perception of the accounting profession depending on their level of maturity. Once again, we refer to Hamilton and ÓHógartaigh $(2009$, p. 916) who explain that auditors are social agents in the accounting field, whose habitus was formed and acquired through the process of inculcation during their educational and training period. 
In a study by Boekowski and Ugras (1992), which examines students' ethical attitudes when faced with common ethical problems found in the accounting profession, it was discovered that ethical attitudes change according to age. We understand that presenting a TFV in financial information implies ethical attitudes and also the application of FV in order to show the TFV enters into the area of ethical issues. Therefore, the results of this study are useful for us in distinguishing changes in perceptions due to maturity. Findings suggest that younger or less mature students tend to be more justice-orientated in their perception of ethical dilemmas while older or more mature students tend to be more utilitarian in their attitudes. That is, younger students had a more idealistic attitude to the conflicts while more mature students were influenced by their working environment.

Then our next hypothesis investigates the effects of maturity on the assimilation of the TFV and FV concepts, and also describe the null hypothesis as a point of departure for the reasoning.

H3: The perception of TFV and FV reached by students and their processing issues do not depend on their degree of maturity.

\subsection{Research method}

Hypothesis one proposes that there are not differences in the perception of TFV and FV reached by students during the learning context. To answer this question, we explore the responses to each question individually considering the complete sample of students. In particular, we examine the mean values, percentages of agreement, percentages of disagreement and mean-comparison t-tests between pairs of questions that include similar information.

Hypotheses two and three propose that there are not differences in the perception of TFV and FV and in their processing issues, according to the educational level and the degree of maturity. Our research assumes that participants receive the information about TFV and FV in a similar way (we do not alter the information presented) because our interest is to detect differences in the performance of the learner. That is, we examine differences driven by educational level and degree of maturity in the critical situation where the level of cognitive load is imposed by very complex tasks. We also include conventional questions that allow us to measure the full comprehension of the subject matter.

To contrast the above hypotheses, we conduct several tests. First, we use univariate tests to examine the undergraduate and postgraduate students' answers to each question and also the answers conditioned by the level of maturity. Second, we run several regression models (specifically, ordinary least squares - MCO) to analyse all the questions together (not question by question) to extend the incidence of the academic level and the degree of the participants' maturity. Previous to the MCO regression models, we apply a factorial analysis that allows us to reduce the initial information content in the questions. The objective is to explore the complete survey but considering a number of factors that contain the information from the questions formulated in the survey.

The estimation of the models takes the following expression:

$$
\begin{aligned}
& \text { TFV perception }=a_{0}+a_{1} \text { Academic level }+a_{2} \text { Maturity degree }+e_{+}(1) \\
& F V \text { perception }=a_{0}+a_{1} \text { Academic level }+a_{2} \text { Maturity degree }+e_{+} \\
& T F V \text { and } F V \text { processing issues }=a_{0}+a_{1} \text { Academic level }+a_{2} \text { Maturity degree }+e_{+}
\end{aligned}
$$


The dependent variables are the factors extracted in the factorial analysis. The independent variables are the academic level that take a value of 1 for postgraduate students and 0 otherwise; and the degree of maturity that takes a value of 1 for over 25 years old (the oldest) and 0 otherwise.

\subsection{Survey design}

Data was collected by means of a questionnaire administered to accounting students between 2006 and 2008 in the final years of the degree course and to students in masters' courses relating to accounting and auditing. Prior studies use the questionnaire technique to evaluate student's perceptions (see, for example, Torres-Coronas and Vidal-Blasco, 2015; Ruíz and Tirado, 2016).

The variables considered in the study are expressed in 11 questions around three hypotheses as explained above. The questions used a 5-point Likert scale from 1 (totally in disagreement) to 5 (completely in agreement). The survey has three sections. The first one deals with the perception of TFV (questions 1-5). The second section deals with the perception of FV (questions 6-8). The last section explores the TFV and FV processing issues (questions 9-11). The complete survey is shown in the annex.

The sample was drawn from four universities in Spain (undergraduate students) and two audit master courses (postgraduate students). In this case, the Auditing School ICJCE (Instituto de Censores Jurados de Cuentas de España) is the most important auditor body. This master course is followed by students as the first step of the exam to attaining the qualification as an auditor. The second and final step is a practical exam taken after three years of practical experience. For this reason, we use inexperienced students (undergraduates) and more experienced students and users having worked in audit firms (postgraduates).

The student filled out a paper version of the survey that was placed on their chairs. We used this approach in an attempt to obtain a large response rate. A total of 324 usable responses were obtained. The participants from the universities and master courses came from different regions of Spain, thus avoiding bias due to geographical location. Furthermore, the profile of undergraduates is different than those of postgraduates because the first are merely students but in the more advanced years of their studies and the second are normally professionals from audit firms in public practice. Therefore, we have two very different groups: pure students (undergraduate) and students with some experience in performing audits but without any responsibility for giving an opinion (postgraduate).

\section{RESULTS}

\subsection{Summary statistics and data issues}

Table 1 shows the sample characteristics. We can see that the sample is balanced regarding the academic level. That is, $54.63 \%$ are undergraduates and $45.37 \%$ are postgraduates. Table 1 also reveals that nearly $62 \%$ are between the age of 17 and 25 , and nearly $38 \%$ are over 25 years old. 
Table 1. Sample characteristics

\begin{tabular}{lcc}
\hline Sample & Observations & \% total \\
\hline Total sample & 324 & $100 \%$ \\
\hline Academic level & & \\
....Undergraduate & 177 & $54.63 \%$ \\
...Postgraduate & 147 & $45.37 \%$ \\
\hline Age (Maturity) & & \\
....Between 17-25 & 200 & $61.73 \%$ \\
....More than 25 & 124 & $38.27 \%$ \\
\hline
\end{tabular}

\subsection{Results of the perception of TFV and FV: unconditioned results}

Table 2 shows the students' answers to questions about whether they agree with statements related to the perception of TFV (Panel A), the perception of FV (Panel B) and the perception of TFV using FV (Panel C). The complete survey is shown in the annex.

The homogeneity of the survey and the degree to which all items measured one factor was established using Cronbach's alpha (Cronbach, 1951). In our study, the alpha coefficients are 0.88 for the TFV, 0.89 for the FV and 0.79 for the perception of TFV using $\mathrm{FV}$, indicating an appropriate reliability.

Table 2, Panel B reveals that students consider that the meaning of $F V$ is explained during the studies (52.16\% agreement in Q6). However, only $41.05 \%$ of the participants consider that an understanding of this concept is reached during the studies (Q7). One surprising finding in the survey is the low score assigned to the appropriate time of learning the concept during the studies (27.78\% of agreement in Q8). Generally, students consider that the concept is not learnt at an appropriate time during the studies. We can interpret the evidence as they would prefer to learn it earlier.

It is logical that, in this section of questions, students that reached low levels of agreement in question 6 would also have obtained low levels of agreement in questions 7 and 8. Evidently, the students perception is that FV is not explained in their studies, which makes it difficult for them to answer the question on whether an understanding of the concept is reached and difficult to answer if it was learnt at an appropriate time in their studies.

The mean-comparison t-tests (not reported) between $Q 1$ that explores if the TFV is studied at an appropriate time during the studies and Q8 that explores if the FV is studied at an appropriate time show statistically significant differences $(p<0.05)$. Also, the mean-comparison t-tests (not reported) between Q3 that explores the understanding of TFV and Q7 that explores the understanding of FV also show statistically significant differences $(p<0.05)$. Therefore, the evidence shows that there are differences in the perception of TFV and FV reached by students during the learning context $(\mathrm{H} 1)$.

Finally, the third section of the survey includes more complex questions and deals with the TFV and FV processing issues. The students need to understand and process the basic accounting concepts in order to find a solution for the presentation of the information in the financial statements. Table 2, Panel C illustrates that $54.63 \%$ of the students consider that the concept of FV offers more to the financial statements than historical cost (Q9), also $66.98 \%$ agree (moderately or strongly) that the annual accounts prepared according to FV can show a TFV (Q10), and $50.31 \%$ agree 
(moderately or strongly) with the fact that financial accounts prepared according to FV show the TFV better than those prepared according to historic cost and other methods (Q11). It seems logical that the response to $Q 9$ was similar to the response to Q11. Both have similar percentages of agreement $(54.63 \%$ in $Q 9$ and $50.31 \%$ in Q11) and disagreement $110.50 \%$ in $Q 9$ and $11.73 \%$ in Q11). These preliminary results need further analysis because the answers could be conditioned by the characteristic of the sample, mainly the educational and maturity levels.

\section{Table 2: Exploratory analysis}

\section{Panel A: TFV perception}

\begin{tabular}{cccccccc} 
& Obs. & Mean & S.D. & \% agree & \% desag & F & Sig \\
\hline \hline Q1 & 324 & $3.45^{* * *}$ & 1.135 & 59.87 & 22.84 & 13.54 & 0.00 \\
Q2 & 324 & $3.72^{* * *}$ & 1.193 & 67.90 & 20.68 & & \\
Q3 & 324 & $3.60^{* * *}$ & 1.140 & 62.96 & 19.76 & & \\
Q4 & 324 & $3.87^{* * *}$ & 1.032 & 70.99 & 10.50 & & \\
Q5 & 324 & $3.83^{* * *}$ & 1.118 & 70.06 & 15.12 & &
\end{tabular}

\section{Panel B: FV perception}

\begin{tabular}{|c|c|c|c|c|c|c|c|}
\hline & Obs. & Mean & S.D. & $\%$ agree & $\%$ desag & $\mathbf{F}$ & Sig \\
\hline Q6 & 324 & $3.30^{* * *}$ & 1.31 & 52.16 & 29.94 & 48.84 & 0.00 \\
\hline Q7 & 324 & 3.01 & 1.25 & 41.05 & 37.96 & & \\
\hline Q8 & 324 & $2.81^{* * *}$ & 1.12 & 27.78 & 39.81 & & \\
\hline
\end{tabular}

\section{Panel C: TFV perception using FV}

\begin{tabular}{lccccccc} 
& \multicolumn{1}{c}{ Obs. Mean } & S.D. & \% agree & \% desag & F & Sig \\
\hline \hline Q9 & 324 & $3.58^{* * *}$ & 0.97 & 54.63 & 10.50 & 13.87 & 0.00 \\
Q10 & 324 & $3.77^{* * *}$ & 0.88 & 66.98 & 6.48 & & \\
Q11 & 324 & $3.52^{* * *}$ & 0.95 & 50.31 & 11.73 & &
\end{tabular}

The table reports summary statistics on the students where \% agree corresponds to strongly and moderately in agreement ( 4 or 5 in the Likert scale). \% disagreement corresponds to completely and moderately in disagreement ( 1 or 2 in the Likert scale). The asterisks of the mean figure measure the probability that this average is significantly different from 3 , with a level of significance of 1 per cent $(* * *), 5$ per cent $(* *)$ or 10 per cent $(*)$

\subsection{Results of the perception of TFV and FV by academic level and maturity}

\subsubsection{Univariate results}

In this section, we report the results of the difference in the perception of TFV and FV between undergraduates and postgraduates (Table 3) and the difference in the perception of TFV and FV according to varying levels of maturity (Table 4). 
Both Tables show the levels of agreement (moderate and strong agreement) and the levels of disagreement (moderate and strong disagreement) between the two groups of interest. The tables also present the mean, the median, the standard deviation and whether the mean of the responses is different from 3. Finally, the last two columns report the p-values obtained by mean-comparison t-test and non-parametric U-Mann Whitney test. These two tests allow us to examine the differences between the two groups of interest.

Table 3 shows that the percentages of agreement (moderate and strong) are higher for undergraduate students than for postgraduate students. We observe statistically significant differences in most questions depending on the group of participants $(p<0.05)$. Initially, we would assume that higher education level would reduce the corresponding load and ultimately improve performance. However, the evidence shows that the higher the academic level and progress in studies make students more reflexive in regard to the explanation of the two complex concepts examined as well as their correct understanding.

Table 3: Extract Factor and Factor loading

\begin{tabular}{lccc} 
& Factor 1 & Factor 2 & $\begin{array}{c}\text { Factor 3 } \\
\text { TFV perception } \\
\text { using FV }\end{array}$ \\
\cline { 2 - 3 } Q1 & 0.67 & FV perception & \\
Q2 & 0.78 & & \\
Q3 & 0.73 & & \\
Q4 & 0.63 & & \\
Q5 & 0.80 & 0.87 & \\
Q6 & & 0.89 & \\
Q7 & & 0.85 & 0.79 \\
Q8 & & & 0.78 \\
Q9 & & & 0.85 \\
Q10 & & & 1.495 \\
Q11 & & & 13.586 \\
\hline Eigen-value & 3.847 & 18.728 & 67.284 \\
Percentage of variance & 34.969 & 53.697 & \\
Cumulative percentage & 34.969 & & \\
\hline
\end{tabular}

Rotation method: Varimax with Kaiser Normalization. Rotation converged in 5 iterations.

The answers given in the third section require special attention because it includes more complex questions and deals with the TFV and FV processing issues. Table 3 shows that $59.32 \%$ of the undergraduates consider that the concept of FV offers more to the financial statements than historical cost (Q9) compared to $48.98 \%$ of postgraduates. Also, $72.32 \%$ of undergraduates agree (moderately or strongly) with the fact that the annual accounts prepared according to FV can show a TFV (Q10) compared to $60.54 \%$ of postgraduates. The differences are statistically significant between undergraduates and postgraduates $(\mathrm{p}<0.05)$.

The findings reveal that novices and experts respond in a different way although the information is presented using the same structure. The results could be explained through the different mental structures that novices and experts use to solve a problem (see e.g. Simon and Simon, 1978; Larkin et al., 1980). As we discuss later, the learning 
material, handbooks, schemes and the way the information is presented became a key element to make the processing issues easier and to achieve a correct understanding of the complex concepts.

Table 4 also shows that all responses are conditioned to the age of the surveyed population. The percentages of agreement (moderate and strong) are higher for students between the age of 17 and 25 than for students over 25 . We observe statistically significant differences in most responses depending on the student's age $(p<0.05)$. Again, we refer here to the third section due to its importance. Table 4 reveals that agreement by novice students is higher than by more mature students. For example, question eleven (Q11) asks if the financial accounts prepared according to FV show better the TFV than those prepared according to historic cost and other methods. The $54.50 \%$ of novice students agree (moderately or strongly) with the question and the percentage decreases to 43.55 for more mature students. The differences are statistically significant depending on the student's age $(p<0.05)$.

\section{Table 4: The influence of academic level and Maturity degree on TFV's and FV's perceptions}

\begin{tabular}{|c|c|c|c|c|c|c|}
\hline & \multicolumn{2}{|c|}{ TFV perception } & \multicolumn{2}{|c|}{ FV perception } & \multicolumn{2}{|c|}{$\begin{array}{c}\text { TFV perception } \\
\text { using FV } \\
\end{array}$} \\
\hline & coef & $\mathrm{t}$ & coef & $\mathrm{t}$ & coef & $\mathrm{t}$ \\
\hline $\mathrm{c}$ & $0.23^{* * *}$ & 2.91 & $0.38^{* \star \star}$ & 4.91 & $0.13^{*}$ & 1.63 \\
\hline Academic level & $-0.27^{* *}$ & -2.45 & $-0.29^{* \star *}$ & -2.74 & $-0.22^{* *}$ & -1.96 \\
\hline Maturity degree & $-0.29^{* *}$ & -2.50 & $-0.64^{* \star *}$ & -5.81 & -0.08 & -0.72 \\
\hline Adj. $R^{2}$ & 4.09 & & 13.20 & & 1.00 & \\
\hline $\mathrm{F}$ & 7.89 & & 25.56 & & 2.63 & \\
\hline Sig. & 0.00 & & 0.00 & & 0.07 & \\
\hline
\end{tabular}

The table reports the OLS estimates of the effects of Academic level and Maturity on TFV and FV perception. The dependent variables are the factors extracted in the factorial analysis i.e. TFV perception (first column); F2: FV perception (second column), and TFV perception using FV (third column). The independent variables are the academic level and the maturity of the participants. The asterisks represent the statistical significance at 1 per cent $(* * *), 5$ per cent $(* *)$ or 10 per cent $\left(^{*}\right)$. The VIF (vector of inflation factor) does not exceed 2 . Then, we can conclude that multicollinearity is not a concern in the OLS regression

The answers obtained for Q10 are particularly relevant in this study. We would expect a much higher level of agreement to this question if students had correctly assimilated the concept because it is quite clear that, by using the FV concept, we can obtain a TFV. Another result here is that the level of agreement is slightly higher for the less experienced and the less mature students. In a previous study whereby this question was posed to auditors (i.e. more experienced and more mature accounting professionals) an $84.44 \%$ agreement was achieved. This difference between auditors and students is statistically significant (Gonzalo Angulo et al., 2017). What we are observing therefore is that the less mature and inexperienced individuals give a higher level of agreement to this question than the postgraduates and then the agreement level is raised again when auditors are questioned. We are in fact looking at a learning curve here in the learning process. We have already observed that novices tend to stay 
closer to the rules while more expert individuals are more sceptical in their understanding. If we go a step further by introducing previous research with auditors, we are in fact seeing that scepticism is then reduced and the response nears what we would have expected had this concept been assimilated correctly. The auditors' responses also reflect what happens in practice. Our results show that there is a learning curve in the assimilation of these concepts depending on maturity and experience.

Our proposal, by introducing previous research on the CLT, would be to improve the process of assimilation of these concepts in order to shorten the time from getting from one end of the curve to the other. We do not at this stage suggest the elimination of the curve completely because it may be a necessary part of the assimilation process; we simply suggest getting to the expected point earlier. We believe that this can be obtained by improving learning material and introducing case studies dealing with these complex areas. The introduction of schemes would also help here in both education material and the standards themselves. By doing this, we will be reducing the different loads at an earlier stage in the assimilation process and therefore benefiting the overall interpretation of the financial information.

\subsubsection{Multivariate results}

In this section, we reinforce previous results using a multivariate methodology: factorial analysis and MCO regressions. Consistent with previous research that applies factorial analysis to measure the meaning or the perception of accounting concepts (see e.g. Houghton, 1987 for the cognitive meaning of TFV), we use the data reduction process to test the perception of the complex accounting concepts.

The eleven questions were analysed using a Principle Components Analysis with Varimax Rotation. Prior to performing the analysis, the suitability of the data for factor analysis was assessed. That is, we have inspected the correlation matrix in order to assist in determining whether factor analysis was warranted by showing items that were highly correlated. The correlation matrix is also useful for the selection (or exclusion) of items for the various factors. Based on eigenvalues greater than 1 and scree plot criteria, three factors were found to capture 67.28 percent of the total variance. The Kaiser Meyer Olkin (KMO) index was 0.765 , and Bartlett's test of sphericity (chi-square) gave a value of 1530.647 (degrees of freedom, $d f=55$ ), significant at $p=0.00$ (see Barlett, 1954).

The first factor is linked to the perception and assimilation of TFV (labelled TFV perception). The items that loaded heavily on this factor included 'the TFV is the final objective of the financial statements is learnt during the studies-Q5' with a factor loading of 0.80 , and 'the TFV concept is given a lot of importance in accounting studies' with a factor loading of 0.732 . The first factor explains 34.969 percent of the common variance shared by the items in the analysis.

The second factor represents the perception and assimilation of FV (labelled FV perception). All items were loaded heavily on this factor. This factor explains 18.729 percent of the common variance shared by the items in the analysis. The third factor represents the perception of TFV using FV (labelled TFV perception using FV). This factor explains 13.589 percent of the common variance shared by the items in the analysis. 


\section{Table 5: Test of difference in the perception of the meaning of the concept TFV and FV between undergraduates and postgraduates}

Panel A: TFV perception

\begin{tabular}{|c|c|c|c|c|c|c|c|c|c|c|c|c|c|c|}
\hline & & & Undergra & luate & & & & & Postgr & aduate & & & $\mathrm{p}-\mathrm{v}$ & lue \\
\hline & $\mathbf{N}$ & $\%$ agree & $\%$ desag & Mean & Median & S.D. & $\mathbf{N}$ & $\%$ agree & $\%$ desag & Mean & Median & S.D. & t-mean & $\begin{array}{l}\text { U-Mann } \\
\text { White }\end{array}$ \\
\hline Q1 & 177 & 67.80 & 18.08 & $3.61^{* * *}$ & 4.00 & 1.08 & 147 & 50.34 & 28.57 & $3.25^{* *}$ & 4.00 & 1.17 & 0.00 & 0.00 \\
\hline Q2 & 177 & 75.14 & 15.25 & 3.91 & 4.00 & 1.16 & 147 & 59.18 & 2 & 3. & 4.00 & 1.19 & 0.00 & 0.00 \\
\hline Q3 & 177 & 71.75 & 14.12 & $3.81^{* * *}$ & 4.00 & 1.12 & 147 & 52.38 & 26.53 & $3.35 * * *$ & 4.00 & 1.12 & 0.00 & 0.00 \\
\hline Q4 & 177 & 71.75 & 10.73 & $3.92^{* * *}$ & 4.00 & 1.04 & 147 & 70.07 & 10.20 & 3.82 *** & 4.00 & 1.02 & 0.36 & 0.27 \\
\hline Q5 & 177 & 75.14 & 10.17 & $4.01^{* * *}$ & 4.00 & 1.01 & 147 & 63.95 & 21.09 & $3.61 * * *$ & 4.00 & 1.20 & 0.00 & 0.00 \\
\hline
\end{tabular}

Panel B: FV perception

\begin{tabular}{|c|c|c|c|c|c|c|c|c|c|c|c|c|c|c|}
\hline & & & Undergrad & luate & & & & & Postgr & aduate & & & & lue \\
\hline & $\mathbf{N}$ & $\%$ agree & $\%$ desag & Mean & Median & S.D. & $\mathbf{N}$ & $\%$ agree & $\%$ desag & Mean & Median & S.D. & t-mean & $\begin{array}{l}\text { U-Mann } \\
\text { White }\end{array}$ \\
\hline Q6 & 177 & 67.23 & 22.03 & $3.64 * * *$ & 4.00 & 1.30 & 147 & 34.01 & 39.46 & 2.89 & 3.00 & 1.19 & 0.00 & 0.00 \\
\hline Q7 & 177 & 52.54 & 28.25 & $3.28^{* * *}$ & 4.00 & 1.26 & 147 & 27.21 & 49.66 & $2.68^{* * *}$ & 3.00 & 1.15 & 0.00 & 0.00 \\
\hline Q8 & 177 & 35.03 & 33.90 & 2.97 & 3.00 & 1.19 & 147 & 19.05 & 46.94 & $2.62 * * *$ & 3.00 & 1.00 & 0.00 & 0.00 \\
\hline
\end{tabular}

Panel C: TFV perception using FV

\begin{tabular}{|c|c|c|c|c|c|c|c|c|c|c|c|c|c|c|}
\hline & & & Underg & luate & & & & & Postgr & aduate & & & $p-v$ & alue \\
\hline & $\mathbf{N}$ & 6 agree & $\%$ desag & Mean & Median & S.D. & $\mathbf{N}$ & $\%$ agree & $\%$ desag & Mean & Median & S.D. & t-mean & $\begin{array}{l}\text { U-Mann } \\
\text { White }\end{array}$ \\
\hline 29 & 177 & 59.32 & 5.08 & 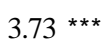 & 4.0 & 91 & 147 & 48 & 17.01 & 3.39 * & 3.00 & 1.01 & 0.00 & 0.00 \\
\hline Q10 & 177 & 72.32 & 4.52 & $3.88^{* * *}$ & 4.00 & 0.86 & 147 & 60.54 & 8.84 & $3.64^{* * *}$ & 4.00 & 0.88 & 0.01 & 0.01 \\
\hline Q11 & 177 & 54.24 & 9.60 & $3.61^{* * *}$ & 4.00 & 0.95 & 147 & 45.58 & 14.29 & $3.41^{* * *}$ & 3.00 & 0.94 & 0.06 & 0.05 \\
\hline
\end{tabular}

The table reports summary statistics on the representativeness of academic level (i.e. undergraduates and postgraduates). The table shows the percentages of agreement (4 or 5 in the Likert scale) and disagreement ( 1 or 2 in the Likert scale), the mean, the median and the standard deviation (S.D.). The asterisks above the mean figure measure the probability that this average is significantly different from 3 , with a level of significance of 1 per cent $(* * *), 5$ per cent $(* *)$ or 10 per cent $(*)$. The last column of each panel shows the $p$-value calculated from the t-tests and U-Mann Whitney test.

The factorial analysis allows us to detect three constructs associated with students' acquisition, evaluation, and weighing of TFV and FV in outcome. In particular, we obtain two factors associated with the judgment in the assimilation of two complex concepts (TFV and FV) and one factor associated with the judgment of the method used to prepare the financial statements. Then we deal with two factors affecting the intrinsic load (the perception of two complex concepts) and one factor affecting the extraneous load (the perception of TFV using different accounting methods).

Finally, the results of the three MCO regression models are reported (Table 6). The model $F$ statistics are significant $(p<0.00)$, indicating that all of them perform well. To test for 
normality, we use the Kolmogorov-Smirnov statistical tests. According to this test, the variables are normal. The Pearson and Spearman correlation between independent variables (academic level and degree of maturity) is 0.226 . The variance inflation factor (VIF) is also used to evaluate the multicollinearity in the model. In our case, the VIF is lower than 2. Then, the multicollinearity is not a problem in the regressions.

The results of Table 6 show that the association between the academic level and the degree of maturity and the dependent variables (the three dimensions named perception of TFV, perception of FV and perception of TFV using FV) are statistically significant. Academic level has a negative and significant effect on dependent variables, suggesting that postgraduate students are associated with lesser perception and assimilation levels of TFV (FV) learning than undergraduates. In other words, undergraduate students tend to perceive that the concepts of TFV and FV are correctly assimilated in the studies. However, postgraduate students could be more realistic about the difficulty to correctly assimilate complex accounting concepts and tend to be more moderate in their responses. The results of the regression analysis confirm the univariate analysis and the second hypothesis.

The estimated coefficient degree of Maturity is negative and significant. The results suggest that the younger students tend to perceive that the concepts of TFV and FV are more correctly assimilated in the studies than older students. The results of the regression analysis confirm the univariate analysis and the third hypothesis. That is, the degree of maturity and experience is important in the perception and assimilation of TFV and FV and affects the responses associated with the correct assimilation of complex concepts during the studies.

The evidence can also be explained using the CLT. The maturity of students and their progress in the studies make them more reflexive in regard to the explanation of the TFV and FV concepts as well as to their understanding during their training. We can interpret these results as a logical learning curve, as already described, in the learning process of accounting. The link between a qualitative assessment (such as the understanding of TFV and FV, complex concepts) depends on their understanding of the concept and the level of maturity of those focusing on accounting and auditing careers.

Moreover, the evidence suggests that the outcome (complexity of the task) is solved using different resources (cognitive capacity). That is, the most inexpert participants need to use all the logical reasoning learnt until this moment in order to complete the task. However, the most expert participants can apply the schemes directly (accounting rules) to complete the task because their experience in solving similar problems enables them to find the solution without analysing all the information. It seems like experts replace the logical reasoning with their experience in solving the problem. This argument has important implications in practice. If the accounting standards allow users to know how to solve the problem without referring to historical information and logical reasoning, the individual judgment and capacity to complete the task is very limited. In addition, when the problem is new and the accounting standard does not permit the completion of the task, the risk of failure is high. Consequently, the accounting standard setters need to anticipate the environment's change by making sure that the accounting standards permit the judgement processing capacity to complete the task. 


\section{Table 6: Test of difference in the perception of the meaning of the concept TFV and FV driven by the maturity.}

Panel A: TFV perception

\begin{tabular}{|c|c|c|c|c|c|c|c|c|c|c|c|c|c|c|}
\hline & \multicolumn{6}{|c|}{ Age (17-25) } & \multicolumn{6}{|c|}{ Age (+25) } & \multicolumn{2}{|c|}{$\begin{array}{l}\text { p-value } \\
\text { U-Mann }\end{array}$} \\
\hline & $\mathbf{N}$ & $\%$ agree & $\%$ desag & Mean & Median & S.D. & $\mathbf{N}$ & $\%$ agree & $\%$ desag & Mean & Median & S.D. & t-mean & $\begin{array}{c}\text { U-Mann } \\
\text { White }\end{array}$ \\
\hline Q1 & 200 & 67.00 & 17.50 & $3.64^{* * *}$ & 4.00 & 1.08 & 124 & 48.39 & 31.45 & 3.15 & 3.00 & 1.16 & 0.00 & 0.00 \\
\hline Q2 & 200 & 76.00 & 14.50 & $3.95^{* * *}$ & 4.00 & 1.08 & 124 & 54.84 & 30.65 & $3.34^{* * *}$ & 4.00 & 1.27 & 0.00 & 0.00 \\
\hline Q3 & 200 & 74.50 & 13.00 & $3.91^{* * *}$ & 4.00 & 1.05 & 124 & 44.35 & 30.65 & 3.12 & 3.00 & 1.11 & 0.00 & 0.00 \\
\hline Q4 & 200 & 70.50 & 10.00 & $3.87^{* * *}$ & 4.00 & 1.03 & 124 & 71.77 & 11.29 & $3.88^{* * *}$ & 4.00 & 1.04 & 0.94 & 0.88 \\
\hline Q5 & 200 & 71.00 & 10.50 & $3.90^{* * *}$ & 4.00 & 1.05 & 124 & 68.55 & 22.58 & $3.72 * * *$ & 4.00 & 1.21 & 0.17 & 0.32 \\
\hline
\end{tabular}

Panel B: FV perception

\begin{tabular}{|c|c|c|c|c|c|c|c|c|c|c|c|c|c|c|}
\hline & & & Age (1 & (7-25) & & & & & Age & $(+25)$ & & & & alue \\
\hline & $\mathbf{N}$ & $\%$ agree & $\%$ desag & Mean & Median & S.D. & $\mathbf{N}$ & $\%$ agree & $\%$ desag & Mean & Median & S.D. & t-mean & $\begin{array}{l}\text { U-Mann } \\
\text { White }\end{array}$ \\
\hline Q6 & 200 & 66.00 & 21.50 & $3.68^{* \star *}$ & 4.00 & 1.23 & 124 & 29.84 & 43.55 & $2.69^{* \star *}$ & 3.00 & 1.20 & 0.00 & 0.00 \\
\hline Q7 & 200 & 52.00 & 30.00 & $3.32^{* \star *}$ & 4.00 & 1.20 & 124 & 23.39 & 50.81 & $2.51^{* \star *}$ & 2.00 & 1.17 & 0.00 & 0.00 \\
\hline Q8 & 200 & 35.50 & 35.00 & 3.04 & 3.00 & 1.10 & 124 & 15.32 & 47.58 & $2.45^{* \star *}$ & 3.00 & 1.05 & 0.00 & 0.00 \\
\hline
\end{tabular}

Panel C: TFV perception using FV

$$
\text { Age (17-25) }
$$

Age (+25)

p-value

N \% agree \% desag Mean Median S.D. $\mathbf{N} \%$ agree \% desag Mean Median S.D. t-mean White $^{\text {U-Mann }}$

\begin{tabular}{l|llllll|llllll|lll} 
Q9 & 200 & 55.50 & 8.00 & $3.66^{* * *}$ & 4.00 & 0.89 & 124 & 53.23 & 14.52 & $3.45^{* * *}$ & 4.00 & 1.08 & 0.06 & 0.22 \\
Q10 & 200 & 67.00 & 4.00 & $3.82^{* * *}$ & 4.00 & 0.84 & 124 & 66.94 & 10.48 & $3.69^{* * *}$ & 4.00 & 0.94 & 0.21 & 0.41 \\
Q11 & 200 & 54.50 & 5.50 & $3.66^{* * *}$ & 4.00 & 0.84 & 124 & 43.55 & 21.77 & $3.29^{* * *}$ & 3.00 & 1.07 & 0.00 & 0.00
\end{tabular}

The table reports summary statistics on the representativeness of maturity level (i.e. age between 17 and more than 25). The table shows the percentages of agreement (4 or 5 in the Likert scale) and disagreement ( 1 or 2 in the Likert scale), the mean, the median and the standard deviation (S.D.). The asterisks above the mean figure measure the probability that this average is significantly different from 3 , with a level of significance of 1 per cent $(* * *), 5$ per cent $(* *)$ or 10 per cent $(*)$. The last column of each panel shows the $p$-value calculated from the t-tests and U-Mann Whitney test.

\section{CONCLUSIONS}

This research investigates the perception and understanding of two fundamental and especially complex accounting concepts, that is TFV and FV by accounting students. Our intention is to detect whether students correctly assimilate the TFV concept perceiving that it is the final objective of the financial information.

The evidence suggests that accounting students consider that TFV is a superior accounting concept over other accounting principles and that the TFV is the final objective of the financial statements learnt during the education process. The evidence also suggests that the participants generally consider that the concept of TFV is learnt at an appropriate time during the studies but the same cannot be said for the FV 
concept. The results are logical in relation to the country being considered and the period when the survey was administered. The mentality of students is consistent with the notion that TFV becomes the 'final objective' of the financial information that was formally introduced into the legislation in 1989. The FV method is more widely used to value certain assets and liabilities after the introduction of IFRS.

The study identifies a pattern of change depending on the academic level and maturity of the participants. In particular, the findings show statistically significant differences in the perception of TFV, perception of FV, and of TFV and FV processing issues depending on academic level (undergraduate and postgraduate students) and maturity. It is noted that the maturity of the students and their progress in their education makes them more sceptical in their responses.

In the final part of our survey, we introduced some questions which went further than asking about the perception of the concepts. They required an understanding of the concepts and the ability to be able to process the information in order to answer them. The answers obtained here, especially in response to one of those questions, is particularly relevant. If the individuals had understood the concepts well, we would have expected a high level of agreement to whether the use of FV can give a TFV. The less mature and inexperienced individuals give a higher level of agreement to this question than the postgraduates. We observe a natural learning process among students which must be respected but efforts can be made to make this development more efficient.

We back up this previous observation by the current evidence existing from previous psychological studies. We refer to the CLT and the expert-novice research which shows how the cognitive load of a novice and an expert differ. We make the proposal to shorten this learning process and to improve the education procedure for these concepts by improving learning material and introducing case studies dealing with these complex areas. The introduction of schemes would also help here in both education material and the standards themselves. By doing this, we will be reducing the different cognitive loads at an earlier stage in the assimilation process and therefore benefiting the overall interpretation of the financial information. Our results clearly back up this previous research and, by knowing how in our case accounting concepts such as TFV and FV are processed by the human mind, can help in how these schemes (or accounting standards in the format of schemes) can be used more effectively from both a professional and educational point of view. The application of CLT in this area could greatly benefit the financial reports prepared.

It would also be interesting to administer the survey in a subsequent period when the IASB accounting standards are being applied in practice in Spain. Also, the way information is presented and, in particular, the assimilation of complex concepts is an interesting field. The evidence could help in the development of accounting standards and in their corresponding application by professionals, lecturers and standard setters in order to improve the understanding and quality of financial information.

\section{REFERENCES}

ALEXANDER, D.; JERMAKOWICK, E. (2006): A True and Fair View of the Principles/Rules Debate. Abacus, Vol. 42 (2): 132-164.

ANDERSON, B.; MALETTA, M.J.; MORENO, K. (2013): A Comprehensive Set of Introductory Financial Accounting Review Exercises: An Effect to Cause Approach, in 
Dorothy Feldmann, Timothy J. Rupert (ed.) Advances in Accounting Education: Teaching and Curriculum Innovations, Vol. 14: 17 - 44.

ARQUERO, J.L.; TEJERO, C. (2011): How well adapted are accounting students for Bologna?, Revista de Educación en Contabilidad, Finanzas y Administración de Empresas, EDUCADE, Vol. 2. 145-156

ARQUERO, J.L.; TEJERO, C. (2016): Estilos de Aprendizaje y Tolerancia a la Ambigüedad de los Estudiantes Universitarios. Diagnóstico y Reflexiones Ante el EEES. Revista de Enseñanza Universitaria, Vol. 28: 7-17.

BARLETT, M.S. (1954): A note on the multiplying factors for various chi square approximations, Journal of the Royal Statistical Society Series B 16: 296-298.

BOOTH, P.; LUCKETT, P.; MLADENOVIC, R. (1999): The quality of learning in accounting education: the impact of approaches to learning on academic performance, Accounting Education, Vol. 8: 277-300.

BORKOWSKI, S.; UGRAS, Y. (1992): The ethical attitudes of students as a function of age, sex and experience. Journal of Business Ethics, Vol. 11 (12): 961-979.

CLOR-PROELL, S.; PROELL, C.; WARFIELD, T. (2010): Financial statement presentation and non-professional investors' interpretation of fair value information. Working paper, University of Wisconsin-Madison.

CRONBACH, L.J. (1951): Coefficient alpha and the internal structure of tests. Psychometrika, Vol. 16 (3): 297-334.

FOURTH COUNCIL DIRECTIVE (EEC) 78/660 Treaty on the annual accounts of certain types of companies [1978] OJ L 222, 14.8.1978, p. 11. Available at: http://eurlex.europa.eu/legal-content/EN/TXT/PDF/?uri=CELEX:01978L066020130701 \&aid $=1407841352451 \&$ from $=E N$

(accessed 19/07/2016).

FREDERICK, D. M. (1991). Auditor's representation and retrieval of internal control knowledge. The Accounting Review, Vol. 66 (2): 240-258.

GARVEY, A. (2012): Los antecedentes de la imagen fiel y su aplicación en España. Madrid: Dykinson.

GARVEY, A.; GONZALO ANGULO, J.A.; PARTE, L. (2017): Cognitive Load Theory: Limiting the Gap between Academics and Students in Accounting and Auditing, Revista de Ciências Empresariais e Jurídicas (RCEJ), Vol. 28: 5-28

GINNS, P. (2006): Integrating Information: A Meta-Analysis of the Spatial Contiguity and Temporal Contiguity Effects. Learning and Instruction, Vol. 16 (6): 51 1-525.

GONZALO ANGULO, J.A.; GARVEY, A.; PARTE, L. (2017): Perceptions of True and Fair View: effects of professional status and maturity in Modeling, Dynamics, Optimization and Bioeconomics III, Springer, forthcoming.

HAMILTON, G.; Ó'HÓGARTAIGH, C. (2009): The Third Policeman: 'The true and fair view', language and the habitus of accounting. Critical Perspectives on Accounting, Vol. 20 (8): 910-920. 
HOUGHTON, K. (1987): True and Fair View: An Empirical Study of Connotative Meaning. Accounting Organizations and Society, Vol. 12 (2): 143-52.

HOUGHTON, K.A.; HRONSKY, J. J. F. (1993): The sharing of meaning between accounting students and members of the accounting profession. Accounting and Finance, Vol. 33 (2): 85-101.

IFRS 13 Fair Value Measurement [2011].

IASB (2006): A Roadmap for Convergence between IFRSS and US GAAP-2006-2008 Memorandum of Understanding between the FASB and the IASB. 27. Available at $\quad[\mathrm{http}: / / w w w$.ifrs.org/Use-around-the-world/Globalconvergence/Convergence-with-US-

GAAP/Documents/MoU.pdf].(accessed19/07/2016).

KALYUGA, S.; SWELLER, J. (2004): Measuring Knowledge to Optimize Cognitive Load Factors during Instruction. Journal of Educational Psychology, Vol. 96 (3): 558568.

KIRSCHNER, P.A. (2002): Cognitive load theory: implications of cognitive load theory on the design of learning. Learning and Instruction, Vol. 12 (1): 1-10.

KOONCE, L.; NELSON, K.K.; SHAKESPEARE, C.M. (2011): Judging the Relevance of Fair Value for Financial Instruments. The Accounting Review, Vol. 86 (6): 2075-2098.

LARKIN, J.; MCDERMOTT, J.; SIMON, D.; SIMON, H. (1980): Models of competence in solving physics problems. Cognitive Science, Vol. 4 (4): 317-348.

LIBBY, R.; EMETT, S.A. (2014): Earnings Presentation Effects on Manager and User Behavior. Accounting and Business Research, Vol. 44 (4): 410-438.

MAINES, L.; MCDANIEL, L. (2000): 'Effects of comprehensive income volatility on nonprofessional investors' judgments: the role of presentation format'. The Accounting Review, Vol. 75 (2): 179 - 207.

PAAS, F.G.W.C.; VAN MERRIEËNBOER, J.J.G. (1994): Instructional control of cognitive load in the training of complex cognitive tasks. Educational Psychology Review, Vol. 6: 351-371

RAGLAND, L.G.; RECK, J.L. (2016): The effects of the method used to present a complex item on the face of a financial statement on nonprofessional investors' judgments. Advances in Accounting, 34 (Sept), pp. 77-89.

RANKIN, M.; SILVESTER, M.; VALLELY, M.; WYATT, A. (2003): An analysis of the implications of diversity for students' first level accounting performance. Accounting and Finance, Vol. 43 (3): 365-393.

RICH, J.S.; SOLOMON, I.; TROTMAN, K. T. (1997): Multi-auditor judgment/decision making research: A decade later. Journal of Accounting Literature 16: 86-126

RUÍZ LOZANO, M.; TIRADO VALENCIA, P. (2016): La percepción de los alumnos sobre la adquisición de competencias del Trabajo Fin de Grado en ADE. Un análisis en 
la Universidad Loyola Andalucía, Revista de Educación en Contabilidad, Finanzas y Administración de Empresas, EDUCADE, Vol. 7. 19-39

SIMON, D.; SIMON, H. (1978): Individual differences in solving physics problems. In R. Sieglar, (Ed.), Children's thinking: What develops? NJ:Erlbaum.

SWELLER, J. (1988): Cognitive Load during problem solving: Effects on Learning. Cognitive Science, Vol 12 (2): 257- 285.

THEURI, P.; WEICKGENANNT A. (2008): Maturity effects on students' perceptions of how accounting scandals impact the accounting profession. Journal of College Teaching \& Learning, Vol. 5 (1): 53-60.

TORRES-CORONAS, T.T.; VIDAL-BLASCO, M.A.V (2015): Percepción de estudiantes y empleadores sobre el desarrollo de competencias digitales en la educación superior. Revista de Educación, Vol. 367: pp. 63-90.

VAN GERVEN, P.M.C; PAAS, F.G.W.C; VAN MERRIËNBOER, J.J.G.; SCHMIDT, H.G. (2000): Cognitive load theory and the acquisition of complex cognitive skills in the elderly: towards an integrative framework. Educational Gerontology, Vol. 26: 503-521.

VAN MERRIENBOER, J.; SWELLER, J. (2005): Cognitive Load Theory and Complex Learning: Recent Developments and Future Directions. Educational Psychology Review, Vol. 17 (2): 147-175.

\section{ANNEX: Survey}

Section 1: Perception of TFV

Q1. True and Fair View is learnt at an appropriate time during the studies

Q2. This concept is given a lot of importance in accounting studies

Q3. An understanding of this concept is reached during the studies

Q4. This concept is a superior accounting principle to the other accounting principles

Q5. That the True and Fair View is the final objective of the financial statements is learned during the studies

Section 2: Perception of FV

Q6. The meaning of Fair Value is explained during the studies

Q7. An understanding of this concept is reached during the studies

Q8. The Fair Value is learnt at an appropriate time during the studies

Section 3: TFV and FV processing issues

Q9. The Fair Value concept offers more to the financial statements than historical cost

Q10. The annual accounts prepared according to Fair Value can show a True and Fair View

Q11. The financial accounts prepared according to Fair Value show better the True and Fair View than those prepared according to historic cost and other methods 